Case Report

\title{
Gnathostomiasis in a Dog in Lusaka Zambia
}

\author{
Alfred Chikweto ${ }^{1}$, Muhammad.I Bhaiyat ${ }^{2}$, Saul Mofya ${ }^{3}$ and Ravindra.N Sharma ${ }^{4}$ \\ ${ }^{1,2,4}$ Pathobiology Academic Program, School of Veterinary Medicine, St. George's University, Grenada \\ ${ }^{3}$ Department of Veterinary Sciences and Public Health, Fort Valley State University, Fort Valley, \\ Georgia, USA
}

Correspondence should be addressed to: Alfred Chikweto; achikweto@sgu.edu

Received date: 4 April 2014; Accepted date: 23 June 2014; Published date: 22 January 2015

Academic Editor: Marcelo Beltrão Molento

Copyright (C 2015. Alfred Chikweto, Muhammad.I Bhaiyat, Saul Mofya, Ravindra.N Sharma. Distributed under Creative Commons CC-BY 4.0

\begin{abstract}
A 6- month -old male mongrel dog was presented with clinical signs of vomiting, anorexia, weakness and chronic weight loss. At necropsy, an ulcerated granuloma containing numerous nematodes was found in the fundus of the stomach. Several worms were also noted in the gastric lumen. Histologically, there was a granulomatous gastritis with intralesional nematodes characteristic of Gnathostoma spinigerum. This is the first report of gnathostomiasis in a dog in Zambia.
\end{abstract}

Keywords: Gnathostoma spinigerum, dog, Zambia.

\section{Introduction}

Gnathostoma spinigerum is a nematode parasite mostly found in the stomach wall of canine and feline definitive hosts (Soulsby, 1982). When eggs passed in feces reach fresh water, first -stage larvae are released which are ingested by small copepods (first intermediate hosts) and develop to secondstage larvae. When the infected copepods are ingested by paratenic hosts like fishes, amphibians, and birds, the larvae develop further to become third-stage larvae which infect the definitive hosts. Third-stage larvae migrate further into the definitive host tissue and finally develop into adults in the stomach wall to complete their life cycle, thereby inciting a localized/focal granulomatous gastritis.

Gnathostomiasis is an emerging food borne zoonotic parasitic disease endemic to Southeast Asia including Thailand, Vietnam, Philippines, Malaysia, Myanimar, Bangladesh, Cambodia, Laos and Indonesia and has been widely documented in Japan, China and Mexico [De Gorgolas et al., 2003). Outside the endemic areas, gnathostomiasis has recently 
been reported in Zambia, Tanzania and Botswana, often in tourists who had consumed raw marinated or undercooked fresh water fish (Hale et al., 2003; Herman et al., 2009; McCarthy and Moore, 2000)

Gnathostoma spp was first reported in the stomach wall of a tiger from a London Zoo in 1836 (Herman and Chiodin, 2009). In domestic cats and dogs, reports of gnathostomiasis are few. Based on a coprologic survey, Arafa et al (1978) reported a prevalence of $0.7 \%$ in cats in Cairo, Egypt. Case reports for gnathostomiasis in a cat from the USA and 3 cats from Australia have also been documented. (Kirkpatrick et al., 1987; Trueman and Ferris, 1977). The parasite has extensively been reported in dogs, cats and humans in Thailand (Rojekittikhun, 2002). Reported is a case of gnathostomiasis in a dog from a tropical southern African country of Zambia.

\section{Case Report}

A 6 month- old male mongrel dog was presented to the Small Animal Clinic at the School of Veterinary Medicine, University of Zambia with a history of anorexia, vomiting, weakness and chronic weight loss. The usual diet of the dog included kitchen scraps and occasionally fish. As the dog died due to a combination of anemia and gastritis, necropsy was performed. The dog was emaciated and there was generalized pallor. Gross lesions seen in the gastric fundus consisted of an ulcerated, $3 \mathrm{~cm}$, diameter granuloma containing numerous nematodes. Several worms were also noted in the lumen of the stomach.

Tissues from the stomach were fixed in 10\% formalin, embedded in paraffin, sectioned and stained with hematoxylin and eosin. Histopathology revealed granulomatous gastritis characterized by the infiltration of moderate numbers of macrophages and lymphocytes, few eosinophils and a thick band of fibrous connective tissue around the granuloma which were restricted to the tunica muscularis of the stomach. Parasitological evaluation revealed that nematodes were $1-2 \mathrm{~cm}$ long with a head bulb and cuticle spines. Histologically, these parasites had nematode characteristics, including the presence of a body cavity, thin outer wall, cuticle spines, coelomyarian muscles with lateral cords, prominent cuticle ornamentations in form of spines, intestine and gonad. (Fig.1) 

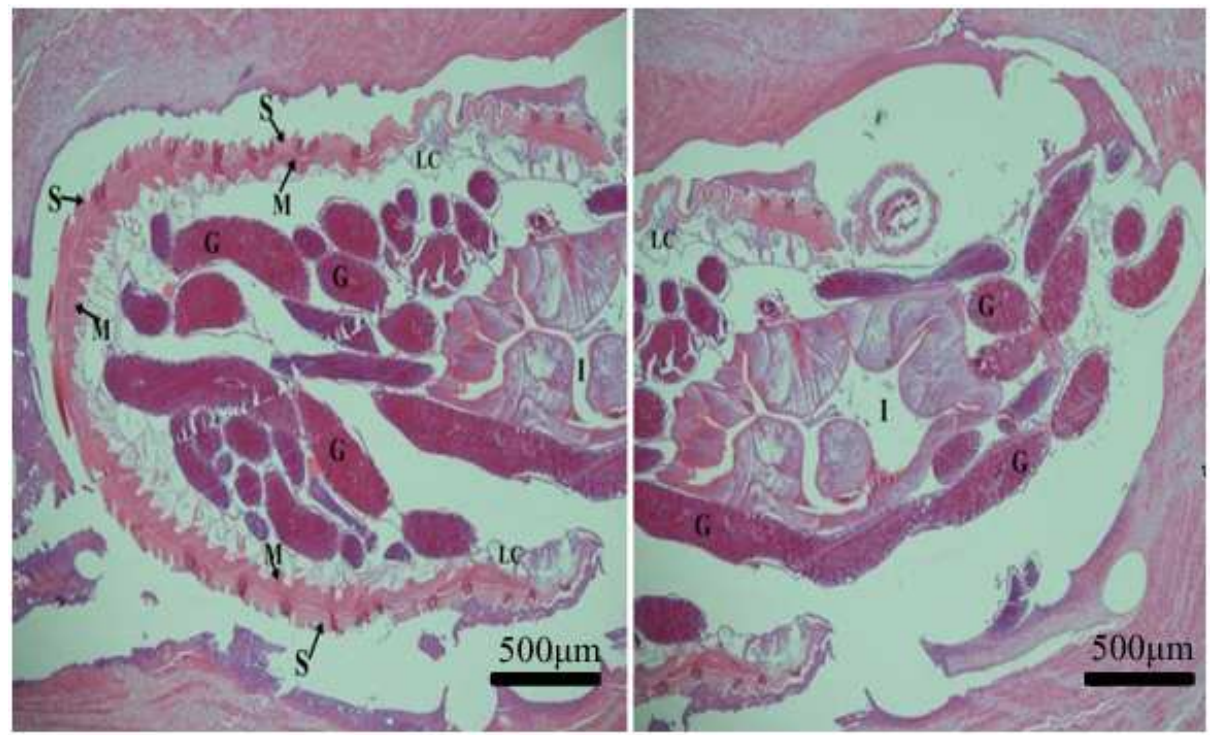

Figure 1: Stomach. Granuloma in the tunica muscularis showing transverse sections of G. spinigerum. Spined cuticle (S) coelomyarian musculature (M), lateral cords (LC), intestine (I) and gonads (G). According to the histologic description of the parasite by Vorachai and Parnpen (2001); Gardiner and Poyton (1999).

\section{Discussion}

This report is the first in a definitive host from Zambia. Since the diet of this dog included fish, it is likely that the dog contracted this parasitosis during one of the feeding episodes; most probably raw or undercooked fish. In Zambia, the host range of infestation by $G$ spinigerum is not known. A recent coprological survey in dogs in Lusaka did not reveal any prevalence of this parasite, indicating that the parasite is rare (Bwalya et al., 2011). However, this parasite is present in Zambia and people should be warned about dangers of consuming raw or undercooked fresh water fish. In addition, dog owners should be encouraged to regularly deworm their pets using fenbendazole and ivermectin (Bowman, 1999). Further research to investigate the prevalence of $G$. spinigerum larvae in fresh water fish in Zambia is recommended.

\section{References}

1. Arafa, M. S., Nasr, N. T., Khalifa, R.; Mahdi, A. H.; Mahmoud, W. S.; Khalil, M. S, (1978) Cats as reservoir hosts of Toxocara and other parasites potentially transmissible to man in Egypt. Acta Parasitologica Polonica, 25(36/46) 383-391.

2. Bowman D.D (1999). Georgis' Parasitology for Veterinarians, W.B Saunders, Philadelphia, USA.

3. Bwalya, E. C, Nalubamba, K. S, Hankanga, C. and Namangala, B. (2011)

4. "Prevalence of canine gastrointestinal helminths in urban Lusaka and rural Katete Districts of Zambia," Preventive Veterinary Medicine, 100 (3-4) 252-255.

5. De Gorgolas, M, O'Connor, F. S. and Garate, T. (2003) "Cutaneous and medullar gnathostomiasis in travelers to Mexico and 
Thailand," Journal of Travel Medicine, 10 (6) 358-361.

6. Gardiner, C.H. and Poyton, S.L. (1999) Morphologic characteristics of nematodes in tissue sections. In: An Atlas of Metazoan Parasites in Animal Tissues. Armed forces Institute of Pathology, USA, pp. 4, 32-34.

7. Hale, D. C, Blumberg, L. and Frean, J. (2003) "Case report: Gnathostomiasis in two travelers to Zambia," American Journal of Tropical Medicine and Hygien, 68 (6) 707709.

8. Herman, J. S, Wall, E. C, van Tulleken, C, Faussett, P. G, Bailey, R. L. and Chiodini, P. L. (2009) "Gnathostomiasis acquired by British tourists in Botswana," Emerging Infectious Diseases, 15 (4) 594-597.

9. Herman, J.S. and Chiodini, P. L. (2009) "Gnathostomiasis, another emerging imported disease," Clinical Microbiology Reviews, 22 (3) 484-492.

10. Kirkpatrick, C.E, Lok, J.B, Goldschmidt, M.H. and Mellman, S. L. (1987) "Gastric Gnathostomiasis in a cat," Journal of
American Medical Association, 190 (11) 1437-1439.

11. McCarthy, J. and Moore, T. A. (2000) "Emerging helminth zoonoses," International Journal for Parasitology, 30 (2000)1351-1360.

12. Rojekittikhun W. (2002) "Current status of Gnathostoma infection in Thailand," Journal of Tropical Medicine and Parasitology, 25(1) 47-52.

13. Soulsby, E.J.L. (1982) Gnathostomiasis. In: Helminthes, Arthropods and Protozoa of Domestic Animals. Bailliere Tindall Publishers, London, pp. 304-305.

14. Trueman, K.F. and Ferris, P.B. (1977) "Gnathostomiasis in 3 cats," Australian Veterinary Journal, 53 (10) 498-499.

15. Vorachai, S. and Parnpen, V (2001) "Various morphological features of Gnathostoma spinigerum in histologic sections: report of 3 cases with reference to topographic study of the reference worm," South-East Asian Journal of Tropical Medicine and Public health, 32 (2) 302-306. 